RIZZO, H. et al. Paralisia de membros pélvicos em reprodutor caprino causada por Linfadenite Caseosa no Estado de Sergipe. PUBVET, Londrina, V. 8, N. 22, Ed. 271, Art. 1812, Novembro, 2014.

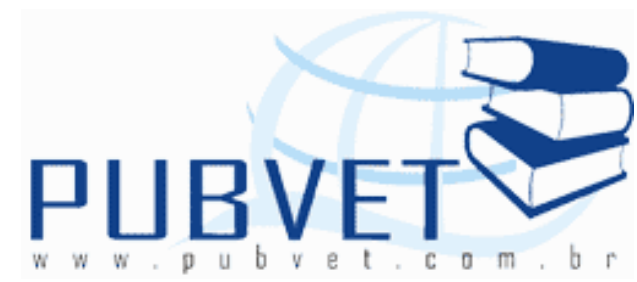

PUBVET, Publicações em Medicina Veterinária e Zootecnia.

\title{
Paralisia de membros pélvicos em reprodutor caprino causada por Linfadenite Caseosa no Estado de Sergipe
}
Huber Rizzoㅜ; Jeferson Silva Carvalho²; Gabriel José Moura Fraga ${ }^{3}$; Mario José Silva Lauria ${ }^{4}$; Pablo Hoentsch Languidey ${ }^{4}$

\begin{abstract}
${ }^{1}$ Professor da disicplina de clínica médica dos ruminantes do departamento de medicina veterinária da Universidade Federal Rural de Pernambuco, Recife-PE, Brasil

2 Médico veterinário autônomo, Aracajú-SE, Brasil

${ }^{3}$ Discente da Faculdade de Medicina Veterinária Pio Décimo, Aracajú-SE, Brasil

${ }^{4}$ Docente da Faculdade de Medicina Veterinária Pio Décimo, Aracajú-SE, Brasil

${ }^{1}$ Correspondência: hubervet@gmail.com
\end{abstract}

\section{Resumo}

Um bode da raça Anglo Lubiana de quatro anos, utilizado como reprodutor em consórcio por quatro criadores, apresentou súbita paralisia dos membros posteriores e conseqüente decúbito esternal durante estação de monta. Ao exame clínico o caprino apresentou sensibilidade na região das últimas vértebras torácicas (T11 a T13) sendo que caudal ao mesmo o animal era insensível e não possuía tônus muscular e cranial ao ponto apresentava sensibilidade e atividades motoras normais. No exame radiológico detectou-se aumento do espaço intervertebral entre T11, T12 e T13 e deslocamento caudal da T13 com conseqüente redução do espaço entre T13 e C1. O caprino não 
RIZZO, H. et al. Paralisia de membros pélvicos em reprodutor caprino causada por Linfadenite Caseosa no Estado de Sergipe. PUBVET, Londrina, V. 8, N. 22, Ed. 271, Art. 1812, Novembro, 2014.

respondeu ao tratamento clínico conservativo e foi eutanasido. A necropsia foi observada fratura bilateral dos processos transversos na região dorsal das últimas vértebras torácicas e extravasamento de material caseoso. Ventral a região, no interior da cavidade torácica, foi observado aumento de volume delimitado por cápsula de dimensões de 7,0 x 4,5cm, disposta medial e a direita das vértebras.O isolamento do material identificou-se Corynebacterium pseudotuberculosis como agente etiológico. O uso consorciado de reprodutores os expõe a diferentes tipos de manejo sanitários, aumentando os risco de infecção e disseminação de enfermidades entre os rebanhos principalmente a Linfadente Caseosa devido sua fácil e rápida disseminação causando grandes prejuízos econômicos e genéticos, principalmente quando há formação de abscessos em vísceras levando ao óbito.

Palavras-chave: bode, Corynebacterium pseudotuberculosis e radiografia

\title{
Paralysis of hind limbs in caprine reproducer caused by Lymphadenitis Caseous in Sergipe State
}

\begin{abstract}
A buck Anglo Lubiana breed of four years, used in intercropping for four owners presented sudden hindlimb paralysis and subsequent sternal decubitus, during the breeding season. In the clinical examination of the billy-goat, the same showed sensitivity until the region of the last thoracic vertebrae (T11 to T13), however, after this region the animal no presented sensibility and haven't muscle tone and in the part cranial presented sensitivity and normal motor activities. In the radiological examination detected an increase in the intervertebral space between T11 and T12 and T12 with caudal displacement and consequent reduction of the space between T12 and T13. The billy-goat did not respond to conservative medical treatment and was euthanized. In the necropsy was seen a bilateral fracture of the transverse processes in the dorsal region of the last thoracic vertebrae and extravasation of caseous material. Ventral to the point of injury, inside of thoracic cavity was observed increased
\end{abstract}


RIZZO, H. et al. Paralisia de membros pélvicos em reprodutor caprino causada por Linfadenite Caseosa no Estado de Sergipe. PUBVET, Londrina, V. 8, N. 22, Ed. 271, Art. 1812, Novembro, 2014.

volume enclosed by capsule of dimensions of $7.0 \times 4.5 \mathrm{~cm}$, in position half right of vertebrae. The insulation material was identified as the etiologic agent Corynebacterium pseudotuberculosis. The use of billy-goats in intercropping exposes them to different types of sanitary management, increasing the risk of infection and spread of Lymphadenitis Caseous among the herds, mainly because it's easy and rapid spread causing major economic and genetic damage, especially when there is formation of abscess in viscera leading to death.

Keywords: bucks, Corynebacterium pseudotuberculosis and radiography

\section{INTRODUÇÃO}

A caprinocultura Sergipana vem buscando sua consolidação, apesar da última colocação no ranking Nordestino com 18.329 cabeças localizadas principalmente no Sertão do Estado, nos último oito anos apresentou crescimento gradativo de $56 \%$ almejando o melhoramento do produto final ao consumidor com conseqüente diminuição do mercado informal que é o predominante para espécie atualmente no Estado (SEBRAE, 2011). Segundo os caprinocultores, o que limita a criação empresarial de caprinos são os problemas sanitários, limitado crédito rural e falta de pastagens cultivadas (OLIVEIRA et al., 1995). Dentre os fatores sanitários devemos considerar o controle das principais enfermidades que acometem os rebanhos caprinos como a Linfadente Caseosa, Artrite-Encefalite Caprina, Ectima Contagioso, Língua Azul, abortos pododermatites, mastites, ceratoconjutivite, micoplasmoses, clostridioses, listeriose, coccidioses, verminoses, ectoparasitas, polioencefalomalacia, toxemia da prenhes, urolitíase e ataxia enzoótica (PINHEIRO et al., 2000; GUEDES et al. 2007; PINHEIRO et al., 2007).

Em relação a linfadenite caseosa, que se caracteriza por uma doença infecto contagiosa crônica que acomete caprinos e ovinos levando ao desenvolvimento de abscessos em linfonodos de conteúdo de material seco, caseoso de cor branco-esverdeada, podendo ser superficiais ou internos e às 
RIZZO, H. et al. Paralisia de membros pélvicos em reprodutor caprino causada por Linfadenite Caseosa no Estado de Sergipe. PUBVET, Londrina, V. 8, N. 22, Ed. 271, Art. 1812, Novembro, 2014.

vezes associados a lesões viscerais e que tem como agente etiológico à bactéria Corynebacterium pseudotuberculosis, os prejuízos podem ocorrer de varias formas como; danos à pele devido às cicatrizes, produção de lã de menor qualidade e condenação de carcaça e vísceras com taxa de desperdício de 3 a $5 \%$ de animais adultos. Além de causar imunossupressão, perda de peso, queda na produção de leite e óbito principalmente nos casos de manifestação visceral e/ou de linfonodos internos, podendo acometer animais de alto valor zootécnico, aumentando assim os prejuízos (BELCHIOR et al., 2006; MACHADO et al., 2001).

Estudos no Nordeste mostram a disseminação da doença nos rebanhos de pequenos ruminantes, onde em $66,9 \%$ das propriedades caprinas do Estado do Ceará os criadores relataram casos de linfadenite (PINHEIRO et al., 2000), no Piauí e Ceará, por meio de palpação de gânglios externos de caprinos, identificou-se $28 \%$ de animais com abscessos nos linfonodos (SILVA \& SILVA et al., 1982) e na Paraíba foi relatado que 7,7\% (49/640) dos pequenos ruminantes do estudo apresentavam evidências clínicas (ANDRADE et al., 2012). Pesquisas em ovinos no Estado de Sergipe demonstraram em rebanho de Nossa Senhora das Dores-SE 8,93\% (10/112) de animais com lesões sugestivas (FREITAS et al., 2011), enquanto que através da inspeção e palpação de 1.229 ovinos de 60 propriedades a ocorrência de animais com as lesões sugestivas foi de 5,19\% (64/1.231) (RIZZO et al., 2013). Levantamentos sorológicos em ovinos através do ELISA indireto demonstraram altas ocorrências como a observada no município de Dormentes-PE com $54,98 \%(171 / 311)$ de ovinos com anticorpos anti-Corynebacterium pseudotuberculosis (MARTINS et al., 2011), no Estado de Minas Gerais com soroprevalências de 43,7\% (SEYFFERT et al., 2010) e São Paulo com 6,1\% (28/457) estudando animais jovens o que justifica a baixa incidência em relação aos outros estudos (CARMO et al., 2010).

A infecção se dá pelo contato de feridas ou mucosas com fômites contaminadas ou mesmo com o contato direto com outros animais afetados, sendo que devemos considerar o aumento do risco de contágio na região 
RIZZO, H. et al. Paralisia de membros pélvicos em reprodutor caprino causada por Linfadenite Caseosa no Estado de Sergipe. PUBVET, Londrina, V. 8, N. 22, Ed. 271, Art. 1812, Novembro, 2014.

nordeste devido à vegetação de caatinga, que pode perfurar o abscesso permitindo a disseminação do agente na criação (UNANIAN et al., 1985).

A linfadenite pode se manifestar na forma cutânea, com o envolvimento principalmente dos linfonodos parotídeos, retrofaringeos e submaxilares devido à contaminação de lesões tegumentares ulceradas, e/ou visceral, através da penetração do agente pelas mucosas respiratórias e digestórias passando pelo linfonodo retrofaríngeo medial atingindo a circulação sanguínea com posterior distribuição de órgão distantes da porta de entrada. É a forma mais complicada da doença, pois os animais podem apresentar sinais clínicos súbitos uma vez que o abscesso passe a comprometer estruturas importantes como o interior da veia aorta, levando a um aneurisma com conseqüente ruptura da veia, encéfalo, causando manifestações nervosas, pulmões e fígado, levando a óbito e emagrecimento progressivo e esôfago causando regurgitação alimentar (ROSA et al., 1989; BELCHIOR et al., 2006; ALVES et al., 2009; DA SILVA et al., 2009a; PINHEIRO et al., 2013 SILVA JÚNIOR et al., 2013).

O diagnóstico é realizado através dos sinais clínicos, citologia, isolamento bacteriano e reação de cadeia da polimerase (PCR) de material aspirado ou drenado do abscesso ou ainda testes sorológicos como o de imunodifusão em gel de agar, hemaglutinação indireta, fixação de complemento, testes de hipersensibilidade e ELISA (SÁ GUIMARÃES et al., 2011).

O tratamento dos animais infectados consiste na drenagem de abscessos, seguido por limpeza e cauterização química, geralmente com iodo a $10 \%$, ou mesmo extirpação cirúrgica do linfonodo afetado, sendo imprescindível cuidados quanto ao contato da secreção com o solo ou fômites (NOZAKI et al., 2000). Outra alternativa de tratamento é a antibióticoterapia, o que não é muito eficiente, apesar de Corynebacterium pseudotuberculosis ser sensível in vitro para quase todos os antibióticos testados, pois características como a variação de linhagens, localização intracelular das bactérias e formação de biofilme reduz a eficácia dos medicamentos, tornando os antimicrobianos ineficientes sob estas condições (LOPES et al., 2011; SÁ GUIMARÃES et al., 2011). 
RIZZO, H. et al. Paralisia de membros pélvicos em reprodutor caprino causada por Linfadenite Caseosa no Estado de Sergipe. PUBVET, Londrina, V. 8, N. 22, Ed. 271, Art. 1812, Novembro, 2014.

Tem-se como objetivo nesse estudo o relato de um caso de paralisia de membros posteriores em reprodutor caprino devido à formação de abscesso causado por Corynebacterium pseudotuberculosis na região ventral das vértebras torácicas de T11 a T13.

\section{RELATO DE CASO}

Foi atendido em 01 de agosto de 2013 no hospital veterinário Dr. Vicente Borelli da Faculdade de Medicina Veterinária Pio Décimo de Aracaju-SE um reprodutor caprino de quatro anos da raça Anglo Nubiana, com queixa de há três dias apresentar súbita paralisia dos membros posteriores e conseqüente decúbito esternal.

Através da anamnese obteve-se o histórico do caprino que foi adquirido de propriedade localizada no Estado da Bahia aos 20 meses de idade e passou a ser utilizado em consórcio como reprodutor por quatro criadores de três municípios Sergipanos. Antes de apresentar o quadro havia participado de duas estações de monta em cada propriedade, sempre com bons índices de fertilidade. Dias antes da paralisia dos posteriores, o reprodutor caprino cobriu 20 fêmeas em uma das propriedades no município de Porto da Folha e foi transportado por $90 \mathrm{~km}$ até Nossa Senhora das Dores para cobertura de outro lote de fêmeas, no entanto após três dias nesse rebanho apresentou quadro de impotência coeundi devido incapacidade de manter-se em estação.

O caprino foi submetido ao exame clínico, constatando que o mesmo apresentava-se alerta e com suas funções vitais dentro da normalidade. $\mathrm{Na}$ palpação dos membros posteriores, notou-se ausência de sensibilidade, tônus muscular e resposta a estímulos dolorosos, com características de paralisia flácida. Na coluna espinhal foi identificado sensibilidade na região das últimas vértebras torácicas (Fig. 1a), manifestada pelo caprino através da contração da musculatura torácica, vocalização e direcionamento do olhar para a região durante a palpação. A partir da localização desse ponto de sensibilidade concluiu-se que caudal ao mesmo o animal era insensível e apresentava 
RIZZO, H. et al. Paralisia de membros pélvicos em reprodutor caprino causada por Linfadenite Caseosa no Estado de Sergipe. PUBVET, Londrina, V. 8, N. 22, Ed. 271, Art. 1812, Novembro, 2014.

ausência de tônus muscular e cranial ao ponto apresentava sensibilidade e atividades motoras normais, inclusive algumas vezes assumindo a posição de "cão sentado" com os membros anteriores apoiados (Fig. 1b).
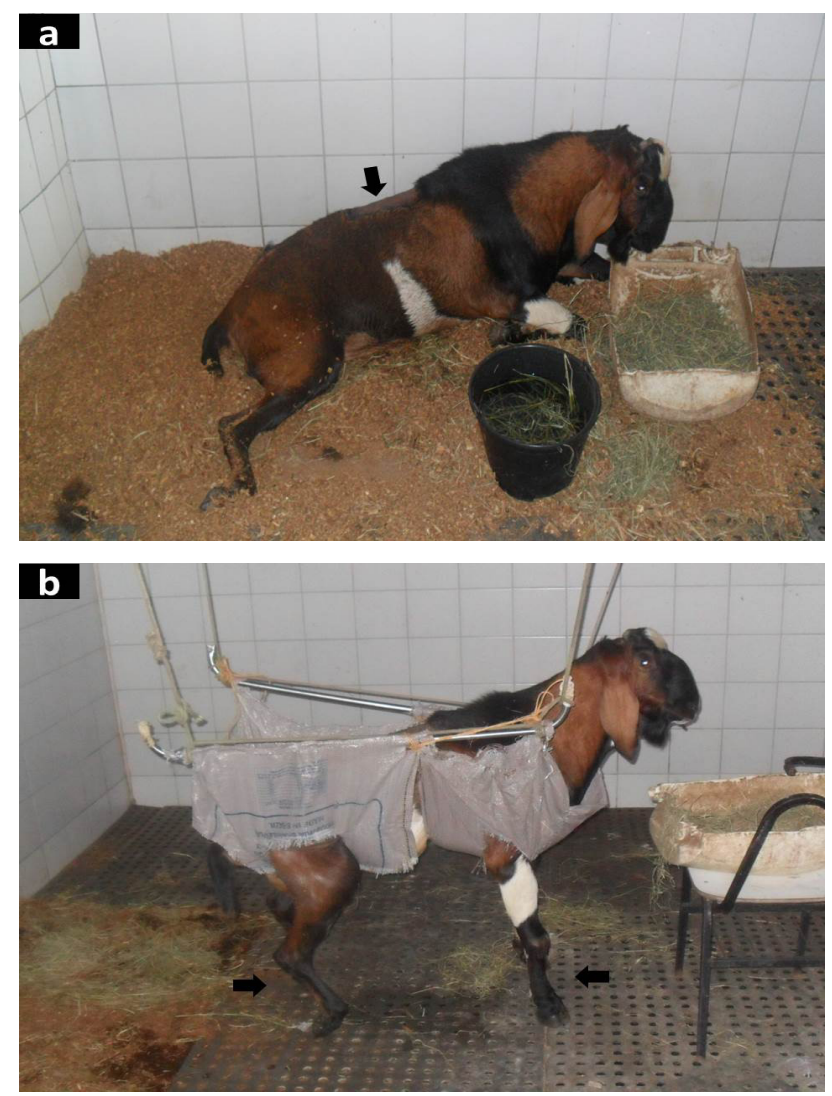

Figura 1: a) ponto de sensibilidade à palpação da coluna espinhal. b) Caprino em giral apresentando flacidez de membros posteriores com conseqüente emboletamento e apoio ao solo de membros anteriores.

Esse quadro de paralisia foi relatado em bovinos nelore do Pará após vacinação contra febre aftosa que levou a formação de abscessos entre L1 e L4 (UBIALI et al., 2011), em bezerros e cordeiros jovens devido abscesso vertebrais secundários a onfaloflebite (MARQUES et al., 2004) e cordeiro devido agenesia da $7^{a}$ vértebra (GREGORY et al., 2006), no entanto o caprino do estudo não possuía histórico de administração de medicamento injetáveis recentemente e tratava-se de caprino adulto sem a presença de focos de infecção em outras partes do corpo. Quadro semelhante de paralisia de 
RIZZO, H. et al. Paralisia de membros pélvicos em reprodutor caprino causada por Linfadenite Caseosa no Estado de Sergipe. PUBVET, Londrina, V. 8, N. 22, Ed. 271, Art. 1812, Novembro, 2014.

membros posteriores foi relatado em ovinos no Rio Grande do Sul, onde à necropsia foi observado um espondilite piogranulomatosa devido abscesso causado por Corynebacterium pseudotuberculosis associada à compressão de medula espinhal entre as vértebras T13 e L1 (SOUZA et al., 2012), região essa semelhante a que o caprino do estudo demonstrou sensibilidade.

No exame hematológico não foram notadas anormalidades quanto ao volume globular $(24 \%)$, volume globular médio $(27,52)$, concentração de hemoglobina corpuscular média $(33,33 \%)$, hemácias $\left(8,72 \times 10^{6} / \mu \mathrm{L}\right)$ e hemoglobina ( $8 \mathrm{~g} / \mathrm{dL}$ ), se opondo aos achados de Da Silva et al. (2009b) que observaram anemia nos animais com linfadenite caseosa. No entanto quanto ao leucograma os achado foram semelhantes do mesmo autor, com a presença de leucocitose por neutrofilia de segmentados $\left(23,25 \times 10^{3} / \mu \mathrm{L}\right.$ sendo $80 \%$ segmentados), que é indicativo de um processo inflamatório ou infeccioso crônico, que é uma das características da infecção por Corynebacterium pseudotuberculosis.

O exame radiológico foi realizado com projeções latero-lateral esquerda e direita da coluna espinhal onde se observou aumento do espaço intervertebral entre T12 e T13 e deslocamento caudal da T13 com conseqüente redução do espaço entre T13 e L1 (Fig. 2).

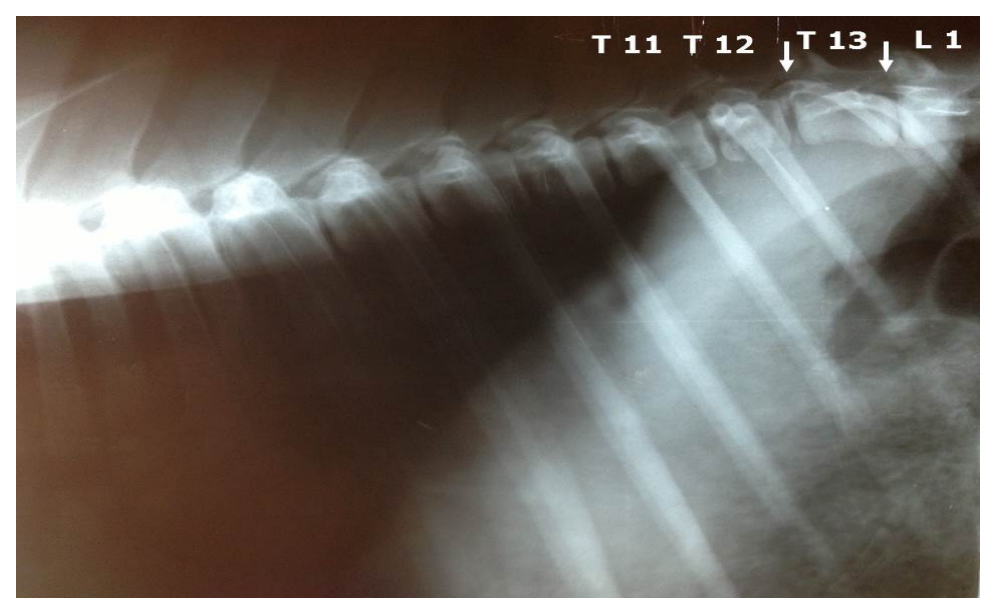

Figura 2: Projeção radiográfica latero-lateral esquerda, demonstrando aumento de espaço intervertebral entre $\mathrm{T} 12$ e $\mathrm{T} 13$ e redução do mesmo entre $\mathrm{T} 13$ e $\mathrm{L} 1$. 
RIZZO, H. et al. Paralisia de membros pélvicos em reprodutor caprino causada por Linfadenite Caseosa no Estado de Sergipe. PUBVET, Londrina, V. 8, N. 22, Ed. 271, Art. 1812, Novembro, 2014.

Desta maneira descarta-se a possibilidade de exostose vertebral que acomete bovinos velhos, geralmente nas vértebras torácicas (T2 e T12) e/ou lombares (L2-L3), que estão sujeitas ao aumento da pressão durante o encurvamento da coluna vertebral no cruzamento levando a fratura da ossificação e conseqüente deslocamento parcial da coluna vertebral e compressão da medula espinhal (RADOSTITS et al., 2002) onde se observa radiograficamente uma massa de opacidade mineral mista localizada dorsal ou ventralmente a vértebra, com margens irregulares e áreas de radiolucência cercado por esclerose (ENGEL et al., 2013).

Durante uma semana foi realizado o tratamento clínico conservativo, visando o combate de algum processo inflamatório e/ou infeccioso na região, com a administração de $2 \mathrm{ml}$ de vitamina B1 (2g/20ml/IM) durante cinco dias, $3 \mathrm{ml}$ de dexametasona $(2 \mathrm{mg} / \mathrm{ml} / \mathrm{IM})$ por três dias consecutivos e três aplicações de oxitetraciclina de longa ação (10mg/kg/IM a cada 48 horas), 3 além de $3 \mathrm{ml}$ de polivitaminico ADEvita. O tratamento local foi realizado com aplicação de pomada analgésica e antiflamatória a base de mentol, cânfora e salicilato de metila diariamente (TID). Após o quarto dia de tratamento, não ocorreu melhora no quadro clínico e para evitar as conseqüências do decúbito prolongado e estimular o apoio dos posteriores, o mesmo foi colocado em um giral (Fig. 1b), e recebeu aplicações diárias de 2,5 ml de ketoprofeno $(10 \mathrm{~g} / 100 \mathrm{ml})$ durante três dias consecutivos. Após uma semana de tratamento intensivo não responsivo o animal se apresentava apático e os sinais de dor ao movimento aumentavam gradativamente, sendo assim realizada a eutanásia.

No exame necroscópico, a região dorsal das últimas vértebras torácicas (T12 e T13) apresentou fratura bilateral dos processos transversos sendo que os mesmos podiam ser retirados facilmente da musculatura após tração com pinça, além de extravasamento de material caseoso por pequena fístula na região (Fig. 3). 
RIZZO, H. et al. Paralisia de membros pélvicos em reprodutor caprino causada por Linfadenite Caseosa no Estado de Sergipe. PUBVET, Londrina, V. 8, N. 22, Ed. 271, Art. 1812, Novembro, 2014.
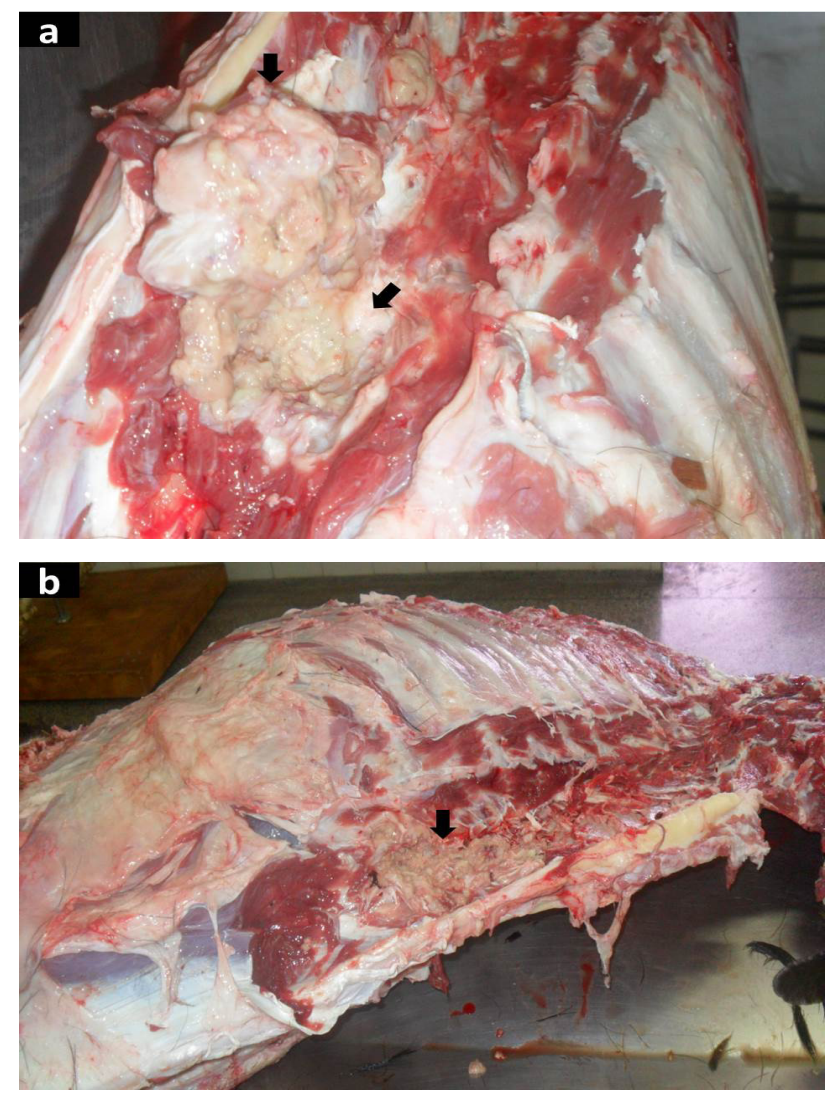

Figura 3: Aspecto dorsal de coluna vertebral caprina. a) Fratura bilateral dos processos transversos de T12 a T13 e presença de material caseoso sob os mesmo e b) região acometida pelo abscesso após retirada dos processos transversos esquerdos.

Ventral a região, no interior da cavidade torácica, foi observado aumento de volume delimitado por cápsula de dimensões de $7,0 \times 4,5 \mathrm{~cm}$, disposta medial e a direita das vértebras (Fig. 4a), que ao ser aberto drenou conteúdo caseoso, não fétido de coloração branco amarelado (Fig. 4b), achados semelhantes aos observados por Souza et al. (2012) em ovinos acometidos por Corynebacterium pseudotuberculosis, a não ser o fato que no caprino do relato não ter sido observado outros focos viscerais de abscesso. 
RIZZO, H. et al. Paralisia de membros pélvicos em reprodutor caprino causada por Linfadenite Caseosa no Estado de Sergipe. PUBVET, Londrina, V. 8, N. 22, Ed. 271, Art. 1812, Novembro, 2014.
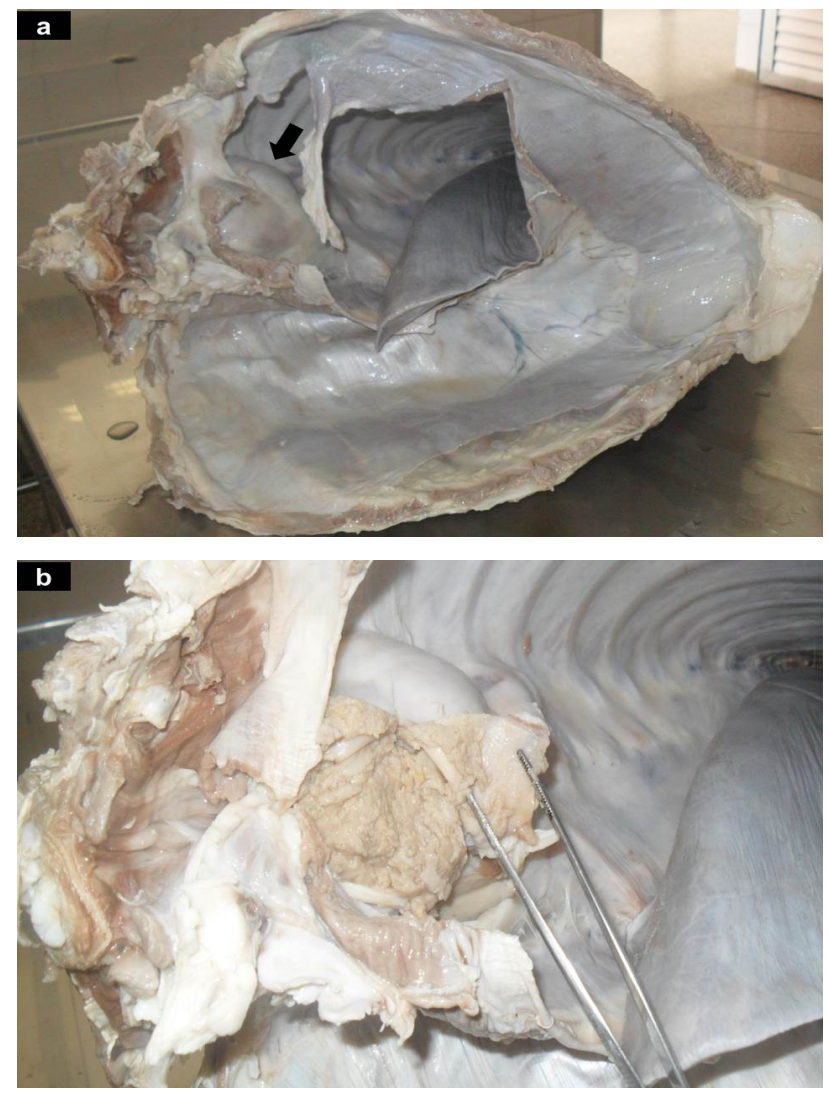

Figura 4: Visão interna da cavidade torácica caprina dissecada. a) abscesso não drenado sob vértebras torácicas (T12 A T13) e b) abscesso aberto sob vértebras torácicas (T12 A T13) com presença de material caseoso.

O material do conteúdo do abscesso foi encaminhado para o diagnóstico através do isolamento bacteriano sendo constatado o crescimento de Corynebacterium pseudotuberculosis. Devido à localização anatômica dos linfonodos intercostais e aórticos torácicos, acredita-se que os mesmos tenham sido acometidos pela infecção, levando a formação do abscesso e conseqüentemente 0 desenvolvimento de espondilite piogranulomatosa associada à compressão de medula espinhal.

Nesse caso é importante ressaltar a epidemiologia da doença onde reprodutores utilizados em consórcios podem estar mais expostos a infecção uma vez que são submetidos a diferentes manejos sanitários a cada reintrodução nos rebanhos, que podem conter animais com ou sem evidências clinicas que não são separados e onde se permita que os abscesso drenem 
RIZZO, H. et al. Paralisia de membros pélvicos em reprodutor caprino causada por Linfadenite Caseosa no Estado de Sergipe. PUBVET, Londrina, V. 8, N. 22, Ed. 271, Art. 1812, Novembro, 2014.

espontaneamente contaminando solo, água, alimentação, pastagens e instalações com secreções nasais, fezes e pus dos abscessos infectando esse reprodutor que poderá disseminar a Linfadenite Caseosa e outras enfermidades aos outros rebanhos que o utilizam em consórcio (SÁ GUIMARÃES et al., 2011; ANDRADE et al., 2012) No caso do caprino do estudo, não se sabe se o mesmo se infectou em uma das quatro propriedades Sergipanas ou em sua propriedade de origem na Bahia, pois no momento de sua aquisição aos 20 meses não foi solicitado exames sorológicos preventivos e o Corynebacterium pseudotuberculosis, que é causador de infecção crônica e infecta animais desde o nascimento, pode ter acompanhado o reprodutor desde jovem sem manifestações clínicas. Isso demonstra a importância da procedência da propriedade de origem e a realização de exames preventivos além da quarentena após a aquisição de animais (SILVA \& SILVA, 1982; DA SILVA et al., 2009a; CARMO et al., 2010).

Ao acometer internamente um reprodutor de alto valor zootécnico, além do prejuízo econômico, há o zootécnico, e para diminuir os risco de perdas e infecção recomenda-se a adoção de medidas sanitárias profiláticas como utilização de quarentena, isolamento de animais com sinais clínicos, drenagem dos abscessos, limpeza com solução anti-séptica associado a administração de penicilina, esterilização do material cirúrgico, uso de cercas de arame liso, bebedouros e instalações sem arestas cortantes, desinfecção sistemática das instalações e uso de agulhas descartáveis individuais (AL-GAABARY et al., 2009; SÁ GUIMARÃES et al., 2011).

\section{CONCLUSÃO}

Conclui-se que a linfadenite caseosa está presente nos rebanhos caprinos Sergipanos e que o uso consorciado de reprodutores, sem a implementação de medidas sanitárias desde a compra e a cada reintrodução nos rebanhos é um risco de disseminação das mesmas. 


\section{REFERÊNCIAS BIBLIOGRÁFICAS}

AL-GAABARY, M.H.; OSMAN, S.A.; OREIBY, A.F. Caseous lymphadenitis in sheep and goats: Clinical, epidemiological and preventive studies. Small Ruminant Research, v. 87, p. 116$121,2009$.

ALVES, L.R.N.; ARAÚJO, M.R.; CAVALCANTI, L.F.L.; GOMES, M.G.T.; PANIAGO, J.D.G.; CARNEIRO, R.A.; ECCO, R. Compressão e estenose esofágica associadas a linfadenite caseosa em ovino. Ciência Animal Brasileira. Suplemento 1, Anais do VIII Congresso Brasileiro de Buiatria, 2009.

ANDRADE, J.S.L., AZEVEDO S.S., TELES J.A.A., HIGINO S.S.S.; AZEVEDO E.O. Ocorrência e fatores de risco associados à infecção por Corynebacterium pseudotuberculosis em caprinos e ovinos do semi-árido paraibano. Pesquisa Veterinária Brasileira, v. 32, n. 2, p. 116-120, 2012.

BELCHIOR, S.E.; GALLARDO, A.; ABALOS, A.; JODOR, N.; JENSEN, O. Actualizacion sobre linfoadenitis caseosa: el agente etiológico y la enfermedad. Revista Veterinaria Argentina, v. 23, n. 224, p. 258-278, 2006.

CARMO, F.B.; GOUVEIA, A.M.G.; GUIMARÃES, A.S.; PAULETTI, R.B.; LAGE, A.P.; RAGOZO, A.M.A.; PORTELA, R.W.D.; GONÇAVES, V.S.P.; AZEVEDO, V.A.C.; HEINEMANN, M.B. Soroprevalência da linfadenite caseosa em criações comerciais de ovinos no Distrito Federal e no Estado de São Paulo. In: CONGRESSO BRASILEIRO DE MICROBIOLOGIA, 25, 2009, Porto de Galinhas. Anais. Rio de Janeiro: Sociedade Brasileira de Microbiologia, 2009.

DA SILVA, T.I.B.; FERNANDES, A.C.C.; ARAÚJO, P.B.; VASCO NETO, H.L.S.; SILVA, D.D.; CUNHA, W.R.X.; SILVA, E.R.R.; MELO, L.E.H.; SANTOS, N.V.M.; SILVA, F.F. Ocorrência de Linfadenite Caseosa em Caprino Jovem criado na Mesorregião Metropolitana do Recife. In: Jornada de Ensino, Pesquisa e Extensão da UFRPE, 9, 2009, Recife. Anais. Pernambuco, 2009a.

DA SILVA, T.I.B.; FERNANDES, A.C.C.; MENEZES, T.M.; VASCO NETO, H.L.S.; SILVA, D.D.; CUNHA, W.R.X.; MELO, L.E.H.; MENDES, E.I. Monitoramento Clínico-Epidemiológico, Hematológico e Etiológico relacionado ao Diagnóstico Diferencial entre Tuberculose Caprina e Linfadenite Caseosa. In: Jornada de Ensino, Pesquisa e Extensão da UFRPE, 9, 2009, Recife. Anais. Pernambuco, 2009b.

ENGEL, S.; RANDALL, E.K.; CUDDON, P.A.; WEBB, B.T.; ABOELLAIL, T.A. maging diagnosis: multiple cartilaginous exostoses and calcinosis circumscripta occurring simultaneously in the cervical spine of a dog. Veterinary Radiology \& Ultrasound, v. 0, n.0, p 1-5, 2013.

FREITAS, L.M.D.; DE JESUS, I.B.; BARBOSA, C.S.S.; VIEIRA, R.T.A.; RIZZO, H. Incidência de Linfadenite Caseosa em Ovinos, da raça Santa Inês, na Fazenda Formosa, em Nossa Senhora das Dores, município de Sergipe. In: CONGRESSO NORDESTINO DE PRODUÇÃO ANIMAL, 6, 2011. Mossoró. Anais. Rio Grande do Norte, 2011.

GREGORY, L.; HENRIQUES, L.C.S.A.; NOGUEIRA, J.S.; BATISTA, C.F.; LIBERA, A.M.M.P.D.; ARAÚJO, W.P.; UNRUH, S.M.; STERMAN, F.A.; HAGEN, S.C.F. Agenesia de $7^{\circ}$ vértebra cervical com compressão de medula. In: CONGRESSO INTERNACIONAL FEINCO, 4, 2009, São Paulo. Anais. São Paulo, 2009. 
GUEDES, K.M.R.; RIET-CORREA, F.; DANTAS, A.F.M.; SIMÕES, S.V.D.; MIRANDA NETO, E.G.; NOBRE, V.M.T.; MEDEIROS, R.M.T. Doenças do sistema nervoso central em caprinos e ovinos no semi-árido. Pesquisa Veterinária Brasileira, v. 27, n. 1, p. 29-38, 2007.

LOPES, C.V.S.; ROSA, M.R.G.; SANTOS, M.R.; CURVELO, V.P.; CUNHA, D.P.; GUERRA, E.F.; SILVA, M.C.A.; PINHEIRO, D.P.M.; CERQUEIRA, R.B. Antibiograma como análise da sensibilidade in vitro de Corynebacterium pseudotuberculosis de caprinos. Revista Acadêmica: Ciências Agrárias e Ambientais, v. 9, n. 3, p. 319-327, 2011.

MACHADO, G.; GRESSLER, L.T.; KIRINUS, J.K.; HERRMANN, G.P. Linfadenite caseosa em ovinos abatidos sob inspeção federal no estado do Rio Grande do Sul - estimativas de perdas. Acta Scientiae Veterinariae, v. 39, n. 2, p. 967, 2001.

MARQUES, L.C.; CADIOLI, F.A.; CASTRO NETTO, A.C.; ÁVILA, L.G.; CANOLA, J.C.; ALESSI, A.C. Abscessos em coluna vertebral de bezerros e cordeiros: aspectos neurológicos. Revista de Educação Continuada CRMV-SP, v. 7, n. 1/3, p. 15-22, 2004.

MARTINS, R.J.; VESCHI, J.L.A.; LANDIM, A.M.S.; CARMO, F.B.; AZEVEDO, V.; MIYOSHI, A.; MEYER, R.; PORTELA, R.; ZAFALON, L.F.; GOUVEIA, A.M.G. Avaliação da presença de anticorpos anti-Corynebacterium pseudotuberculosis em ovinos do Município de Dormentes, PE. In: JORNADA DE INICIAÇÃO CIENTÍFICA DA EMBRAPA SEMIÁRIDO, 6, 2011, Petrolina, Anais. Pernambuco, 2011, p.397-403.

NOZAKI, C.N.; FARIA, M.A.R.; MACHADO, T.M.M. Extirpação cirúrgica dos abscessos da linfadenite caseosa em caprinos. Arquivos do Instituto Biológico, v. 67, n. 2, p. 187-189, 2000.

OLIVEIRA, J. A.M. BRAGA, G.M. DIAS, P.M. Avaliação da adoção das tecnologias usadas pelos criadores de caprinos e ovinos tropicais dos estados da Bahia, Piauí, Pernambuco e Ceará. In: Encontro da Sociedade de Sistemas de Produção, 2, 1995. Anais. Londrina: Sociedade Brasileira de Sistemas de Produção, 1995, p. 128-147.

PINHEIRO, R.R.; ELOY, A.M.X.; ALVES, F.S.F.; ANDRIOLI, A.; SANTIAGO, L.B. Aspectos epidemiológicos da caprinocultura cearense. Arquivo Brasileiro de Medicina Veterinária e Zootecnia, v. 52, n. 5, p. 534-543, 2000.

PINHEIRO, R.R.; ELOY, A.M.X.; ALVES, F.S.F.; ANDRIOLI, A.; SANTIAGO, L.B. Enfermidades infeciosas de pequenos ruminantes: epidemiologia, impactos econômicos, prevenção e controle. Revista Brasileira de Higiene e Sanidade Animal, v. 1, n. 1, p. 44-66, 2007.

PINHEIRO, R.R.; ELOY, A.M.X.; ALVES, F.S.F.; ANDRIOLI, A.; SANTIAGO, L.B. Thoracic aortic aneurysm in a buck associated with caseous lymphadenitis. Arquivos Brasileiro de Medicina Veterinária e Zootecnia, v. 65, n. 3, p. 694-698, 2013.

RADOSTITS, O.M.; GAY, C.C.; BLOOD, D.C.; HINCHCLIFF K.W. 2002. Clínica Veterinária: um tratado de doenças dos bovinos, ovinos, suínos, caprinos e eqüinos, p.677-680. 9a ed. Guanabara Koogan, Rio de Janeiro, 1737p.

RIZZO, H.; CARVALHO, J.S.; HORA, J.H.C.; SANTOS, M.L.R.; ALMEIDA, F.F.; FRAGA, G.J.M.; SANTOS JÚNIOR, N.S.; MACHADO, G.M.. Ocorrência de lesões sugestivas de infecção por Corynebacterium pseudotuberculosis em linfonodos superficiais de ovinos do Estado de Sergipe. In: ENCONTRO SERGIPANO DE ZOOTECNIA, 4, 2013, Aracaju. Anais. Sergipe, 2013.

ROSA, J.S.; JOHNSON, E.H.; ALVES, F.S.F.; SANTOS, L.F.L. Ocorrência de abscesso hepático em caprinos. Pesquisa Agropecuária Brasileira, v. 24, n. 1, p. 63-68, 1989. 
SÁ GUimARÃES, A.; CARMO, F.B.; PAULETTI, R.B.; SEYFFERT, N.; RIBEIRO, D.; LAGE, A.P.; HEINEMANN, M.B.; MIYOSHI, A.; AZEVEDO, V.; GOUVEIA, A.M.G. Caseous lymphadenitis: epidemiology, diagnosis, and control. The IIOAB Journal, v. 2, n. 2, p. 33-43, 2011.

\section{SEBRAE. Estudo de Mercado Sergipe: Potencial de Consumo de Carne, Leite e Derivados, 2011, 113 p.}

SEYFFERT, N.; GUIMARÃES, A.S.; PACHECO, L.G.C.; PORTELA, R.W; BASTOS, .L.; DORELLA, F.A.; HEINEMANN, M.B.; LAGE, A.P.; GOUVEIA, A.M.G.; MEYER, R.; MIYOSHI, A.; AZEVEDO, V.N. High seroprevalence of caseous lymphadenitis in Brazilian goat herds revealed by Corynebacterium pseudotuberculosis secreted proteins-based ELISA. Research in Veterinary Science, v. 88, n. 1, p. 50-55, 2010.

SILVA, M.U.D.; SILVA, A.E.D.F. Linfadenite caseosa em caprinos: observações de dois anos. In: CONGRESSO BRASILEIRO DE MEDICINA VETERINÁRIA, 18, 1982, Camboriú. Anais. Florianópolis: Sociedade Brasileira de Medicina Veterinária, 1982. p. 49-50.

SILVA JÚNIOR, A.B.; DESTRO, C.R.; PAGLIOSA, G.M.; VIOTT, A.M.; GIRALDES, F.F.; TOSTES, R.A. Abscesso cerebral por corynebacterium pseudotuberculosis em um caprino. In: Congresso Brasileiro de Patologia Veterinária, 2, 2013, Curitiba. Anais. Paraná, 2013.

SOUZA, S.O.; LEMOS, L.A.; WOUTERS, A.T.B.; WOUTERS, F.; BOABAID, F.M.; CASAGRANDE, R.A.; WATANABE, T.T.N.; GUERRA, P.; DRIEMEIER, D. Linfadenite caseosa como causa de paralisia de membros pélvicos em ovinos no Estado do Rio Grande do Sul. Acta Scientiae Veterinariae, v. 40, n. 4, p. 1085, 2012.

UBIALI, D.G.; CRUZ, R.A.S.; LANA, MV.C.; MEIRELES, Y.S.; NÉSPOLI, P.B.; SOUZA, M.A.; COLODEL, E.M.; PESCADOR, C.A. Spinal cord compression in cattle after the use of an oily vaccine. Pesquisa Veterinária Brasileira, v.31, n.11, p.997-999, 2011.

UNANIAN, M.M.; SILVA, A.E.D.F.; PANT, K.P. Abscesses and caseous lymphadenitis in goats in tropical semi-arid North-east Brazil. Tropical Animal Health and Production, n. 17, p. 5762, 1985. 